\title{
BMJ Open Prevalence and risk factors of eye diseases in adult patients with obstructive sleep apnoea: results from the SLE.E.P.Y cohort study
} Emilio Pedrotti, ${ }^{1}$ Christian Luigi Demasi, ${ }^{1}$ Enrico Bruni, ${ }^{1}$ Francesca Bosello, ${ }^{1}$
Paolo Plinio Di Sarro, ${ }^{1}$ Mattia Passilongo, ${ }^{1}$ Adriano Fasolo, ${ }^{1,2}$ Nicola Gennaro, ${ }^{3}$
Alessandra De Gregorio, ${ }^{4}$ Marcello Ferrari, ${ }^{5}$ Giorgio Marchini ${ }^{1}$

To cite: Pedrotti E, Demasi CL, Bruni $\mathrm{E}$, et al. Prevalence and risk factors of eye diseases in adult patients with obstructive sleep apnoea: results from the SLE.E.P.Y cohort study. BMJ Open 2017;7:e016142. doi:10.1136/ bmjopen-2017-016142

- Prepublication history for this paper is available online. To view these files, please visit the journal online (http://dx.doi. org/10.1136/bmjopen-2017016142).

Received 30 January 2017 Revised 1 September 2017 Accepted 4 September 2017

\section{(a) CrossMark}

${ }^{1}$ Department of Neurosciences, Biomedicine and Movement Sciences, Eye Clinic, University of Verona, Verona, Italy

${ }^{2}$ The Veneto Eye Bank Foundation, Venezia Zelarino, Italy

${ }^{3}$ Epidemiology Unit, The Veneto Region, Padova, Italy

${ }^{4}$ OU Ophthalmology, San Bassiano Hospital, Bassano Del Grappa, Vicenza, Italy

${ }^{5}$ Unit of Respiratory Medicine, Department of Medicine, University of Verona, Verona, Italy

Correspondence to Dr Emilio Pedrotti; emilio.pedrotti@univr.it

\section{ABSTRACT}

Objectives To assess the occurrence of glaucoma, eyelid, corneal and macular disorders in a cohort of patients with obstructive sleep apnoea (OSA) diagnosed by overnight polysomnography and to investigate into the risk factors for the above eye diseases (EDs).

Design Cross-sectional cohort study between 2014 and 2015.

Setting Unit of Respiratory Medicine and Eye Clinic of the University of Verona.

Participants 431 consecutive patients were considered eligible. Of these, 87 declined to participate, 35 were untraceable and 13 were deceased.

Interventions A complete ophthalmic evaluation of both eyes for each patient.

Primary and secondary outcome measures Bestcorrected distance visual acuity, intraocular pressure, corneal, macular and optic nerve optical coherence tomography, ocular aberrometry, optic nerve laser polarimetry, visual field test, and eyelid examination. Results 296 patients aged $64.5 \pm 12.8$ years, $23 \%$ female and $77 \%$ male, underwent ophthalmic examination. There was $56 \%(n=166)$ prevalence of eyelid disorders, $27 \%(n=80)$ of corneal disorders, $13 \%(n=39)$ of macular disorders and $11 \%(n=33)$ of glaucoma. Advancing age was not associated with the severity of OSA, while significant differences were found for gender, body mass index, Oxygen Desaturation Index, smoking habit, hypertension and diabetes. Severe OSA was significantly associated with glaucoma (OR, $95 \% \mathrm{Cl} 1.05$ to 5.93 , $\mathrm{p}=0.037$ ).

Conclusions EDs were more prevalent in our patinets with OSA than in the general population. Severe Apnoea/ Hypopnoea Index level seemed to play a role as risk factor only for glaucoma.

\section{INTRODUCTION}

Obstructive sleep apnoea (OSA), also referred to as obstructive sleep apnoea-hypopnoea syndrome, is a highly prevalent disorder characterised by repetitive obstruction episodes of the upper airway resulting in oxygen desaturation, arousals from sleep, and daytime
Strengths and limitations of this study

- This is a cross-sectional cohort study that provides prevalence and risk factors of eye disease in patients diagnosed with obstructive sleep apnoea using overnight polysomnography.

- Each patient had a complete ophthalmic evaluation of both eyes.

- The study was carried out in a university setting, and it was possible that our patients were a subgroup of obstructive sleep apnoea population.

symptoms such as excessive sleepiness, poor concentration and fatigue. ${ }^{1}$ Age, gender and obesity are recognised as the strongest risk factors in OSA. ${ }^{2}$ Recent data from the USA and Europe suggest that $14 \%-49 \%$ of middleaged men have clinically significant OSA. ${ }^{3}$

The diagnosis of OSA requires the combined assessment of relevant clinical features and the objective demonstration of abnormal breathing during sleep. Current evidence supports the view that clinical assessment alone does not suffice to make a diagnosis, nor does it provide an objective staging of clinically significant OSA. Currently overnight polysomnography (PSG) is the gold standard for the diagnosis.

The association between OSA and eye diseases (EDs) was first described in 1997 by $\mathrm{McNab}^{4}$, who reported OSA in eight patients with floppy eyelid syndrome (FES) and FES in $1 / 20(5 \%)$ patients with OSA.In the same year, Robert et a $\bar{\varphi}$ reported an increased prevalence of eyelid laxity in patients with OSA requiring treatment for primary open-angle glaucoma (POAG). ${ }^{5}$ Afterwards, the association between sleep disorders and EDs was increasingly reported. ${ }^{6}$ Studies in patients with OSA determined that $2 \%$ had keratoconus (KG) ${ }^{7} 2 \%-16 \% \mathrm{FES}^{8}, 2 \%-20 \%$ POAG 
or normal tension glaucoma (NTG), ${ }^{9}$ and $16 \%$ an increased risk of developing non-arteritic anterior ischaemic optic neuropathy (NAION).$^{10}$

There is an emerging interest in the epidemiological and clinical evidence for an association between OSA and EDs. However, due to its implication in diagnostic and therapeutic management, it remains unclear whether there are common pathophysiological links and/or the same risk factors and/or whether they are accidentally associated. Studies that investigated into the possibility of there being underlying mechanisms have several limitations due to selection or observer bias, misclassification of patients, sample size or poor statistics. Some of the main weaknesses are due to methodological considerations as to the diagnostic criteria for OSA and EDs, or from studies that only estimated OSA by questionnaire, rather than following instrumental diagnostic procedures. Furthermore, no studies correlate the severity of OSA with the occurrence of EDs.

Therefore, the SLEep apnoea and Eye Pathologies studY (SLE.E.P.Y) was set up to estimate the prevalence and risk of eyelid disorders, corneal disorders, glaucoma, macular and optic nerve disorders in patients diagnosed with OSA by PSG.

\section{METHODS}

SLE.E.P.Y was a cross-sectional cohort study of adult patients diagnosed with OSA assessed for EDs (eyelid disorders, corneal disorders, glaucoma, macular and optic nerve disorders) at the University Eye Clinic between 2014 and 2015. All patients were previously diagnosed with OSA at the sleep clinic of the same university following overnight PSG because of breathing disorders during sleep and/ or suspected OSA. Any patients suspected of having sleep disorders other than OSA (central sleep apnoea, complex or mixed sleep apnoea, and patients with craniofacial deformations) were excluded. The study was carried out in agreement with the tenets of the Declaration of Helsinki. Patients' written informed consent was obtained. Our Institutional Review Board/ethics committee approved the study.

All patients underwent PSG, which lasted a minimum of 6 hours. It was started at 23:00 and a portable device (Embletta-PSD Somnologica, Sapio Life, Reykjavik, Iceland) was used to record nose and mouth airflow, chest and abdominal movement, body position, heart rate, Oxygen Desaturation Index and snoring time. Prior determination of whether the patients were appropriate candidates for unattended portable monitoring was performed by an experienced clinician, according to the American Academy of Sleep Medicine Portable Monitoring Task Force. ${ }^{11}$ Polysomnograms were analysed and Apnoea/ Hypopnoea Index (AHI) was calculated as the number of obstructive apnoea episodes (complete cessation of airflow for at least 10s) and of hypopnoea episodes (an airflow reduction of $>50 \%$ for at least $10 \mathrm{~s}$ with a decrease in oxygen saturation of $>3 \%$ ) despite ongoing inspiratory efforts per hour of sleep. ${ }^{12}$ An AHI of $\geq 5$ events/hour was considered suggestive of OSA, defined as mild (5-14), moderate (15-30) or severe (>30).

A complete ophthalmic evaluation was carried out for each patient, including best-corrected distance visual acuity (BCDVA) based on the logMAR chart, and slit lamp biomicroscopy of the anterior and posterior segment, including intraocular pressure (IOP) using a Goldmann applanation tonometer after topical administration of oxybuprocaine at $0.4 \%$ and fluorescein at $2 \%$ with the patient in a sitting position. Corneal examination included an assessment of apical keratometry, vertical symmetry index and surface asymmetry index using corneal topography (Eye Top, CSO, Florence, Italy), assessment of minimal pachymetry and posterior elevation (PE1 and PE2) using corneal optical coherence tomography (Visante Omni, Carl Zeiss, Oberkochen, Germany), and assessment of coma and root mean square using ocular aberrometry (KR-1W, Topcon, Tokyo, Japan). An optic nerve laser polarimetry (Gdx VCC, Carl Zeiss Meditec, Dublin, California, USA) was used to record the nerve fibre indicator (NFI). The average thickness of the retinal nerve fibre layer (RNFL) of the four quadrants (superior, nasal, inferior and temporal) was evaluated by optical coherence tomography (Spectralis SD-OCT, Heidelberg Engineering, Heidelberg, Germany). Mean deviation and pattern SD were calculated by the 30-2 SITA-Standard Humphrey Visual Field (VF) test (Carl Zeiss Meditec). The VF test was repeated if significant fixation losses and/ or false positives or negatives were $>15 \%$. Macular thickness and volume were recorded using optical coherence tomography (Spectralis SD-OCT). Eyelid examination was performed by evaluating horizontal distraction from the ocular globe of the upper and lower eyelids, and the easy eversion sign of upper eyelid (easy distortion and eversion with minimal superolateral traction).

The presence of abnormal corneal thickness and abnormal anterior or posterior ectasia, without corneal inflammatory signs, was considered indicative of a corneal ectatic disorder according to the Global Delphi Panel of Keratoconus and Ectatic Diseases. ${ }^{13}$ The criteria used to define glaucoma were alteration of VF (paracentral scotoma, nasal step or altitudinal defects) in absence of neurological lesion to explain the VF defect and/or glaucomatous cupping within the optic disc accompanied by an NFI of $>50$ and/or defects in the RNFL thickness according to criteria for early diagnosis. ${ }^{14}$ The criteria used to define macular disorders were non-physiological macular profile, a central subfield retinal thickness of $>315 \mu \mathrm{m}$ and a total macular volume of $>3.19 \mathrm{~mm} .{ }^{15} 16$ Diagnosis of any anterior NAION was made following the clinical examination of fundus oculi, and the measurement of both the $\mathrm{VF}$ and of the BCDVA.

A horizontal distraction of $>5 \mathrm{~mm}$ for the upper lid and of $>6 \mathrm{~mm}$ for the lower lid was considered indicative of increased laxity. ${ }^{17}$ FES was defined as the presence of the easy eversion sign of the upper eyelid and the presence of large papillae in the same eyelid conjunctiva. ${ }^{18}$ 
Clinical and instrumental exams were performed by experienced ophthalmologists and a blind assessment of the results was carried out by two ophthalmologists who were not directly involved in patients' examination. A diagnosis of ED was confirmed only when the two ophthalmologists were in agreement.

Results for categorical variables were expressed as counts and percentages, and the $\chi^{2}$ test was used to assess any difference in demographics and clinical characteristics in terms of AHI levels (mild, moderate and severe OSA) in the study group. The individual prevalence of ED was evaluated, and the CI calculated through normal approximation interval. Each patient was considered prevalent in case of at least one eye being affected. The risk factors of ED were calculated by logistic regression analyses. The independent variables were gender, age, body mass index (BMI), AHI, smoking status and any comorbidities. Multivariable model was adjusted for gender, age, BMI and hypertension as possible confounders, introduced in the model as categorical variables. We performed logistic analyses pondering for patient eyes, and multivariable logistical regression with clustering was used to calculate the adjusted OR for each of the four study outcomes (eyelid disorders, corneal disorders, glaucoma, macular and optic nerve disorders). The $\mathrm{p}$ value was set at 0.05 and the CIs calculated at 95\%. The Stata V.13 statistical software was used to analyse the data.

\section{RESULTS}

A total of 431 consecutive patients diagnosed with OSA were considered eligible for the study. Two hundred and ninety-six (69\%) underwent ophthalmic examination (figure 1). Participants did not differ significantly from non-participants. The main reason for exclusion was refusing to participate. The majority of the patients refused due to deambulation difficulties and/or need of parents' assistance. The majority of examined patients were male $(77 \%)$, with mean (SD) and median age of $62.2(14.0)$ and 65.6 years, respectively. Table 1 shows patients' baseline characteristics according to the levels of AHI. A total of 233 (79\%) patients had least one main ED and $50(21 \%)$ of them were under continuous positive airway pressure treatment. Of the 296 patients, 32 (11\%) had both eyelid and corneal disorders, 7 (2\%) all EDs except NAION, and $3(1 \%)$ were affected by NAION. The prevalence of ED is reported in table 2. Patients with KC had BCDVA of 1.0 logMAR and 25/33 (75.8\%) patients with glaucoma had been newly diagnosed. No optic disc oedema was observed. Table 3 shows the frequency of AHI level for EDs. The multivariable analysis demonstrated that a severe AHI level was associated to glaucoma.

\section{DISCUSSION}

To the best of our knowledge, this study was carried out on the largest cohort of patients with OSA diagnosed by PSG, evaluated for EDs. It was observed that most of the patients with OSA had eye involvement, confirming the epidemiology of EDs reported by the literature in this group of patients. ${ }^{8} 91319$ A higher prevalence of OSA in male, obese, smoker, hypertension or patients with diabetes was also shown, confirming the epidemiology reported by the literature. ${ }^{2}$

Eyelid disorders were observed to be the most frequent ED. About $50 \%$ of patients had a diagnosis of eyelid hyperlaxity or FES. It has been hypothesised that hypoxia, reperfusion-induced injury and increased level of leptin have a causal effect on the development of FES as they lead to an upregulation of matrix metalloproteinases (MMPs) and C

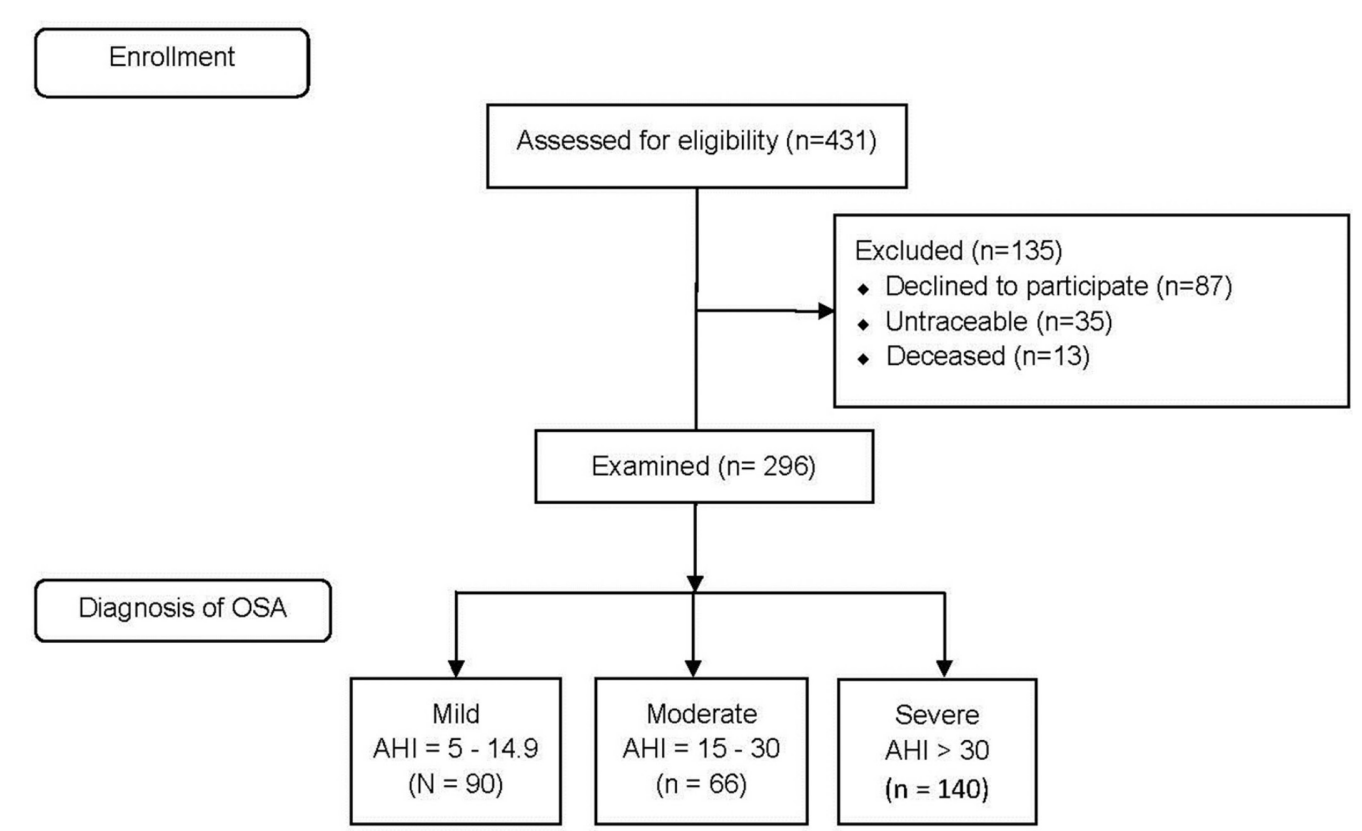

Figure 1 Flow diagram of the progress of all participants through the study. AHI, Apnoea/Hypopnoea Index; OSA, obstructive sleep apnoea. 
Table 1 Characteristics of patients according to the severity of OSA $(n=592)^{\star}$

\begin{tabular}{|c|c|c|c|c|}
\hline & \multicolumn{3}{|c|}{ AHI level, events/hour } & \multirow[b]{2}{*}{ Exact $p$} \\
\hline & $\begin{array}{l}5-14.9 \\
\mathrm{~N}=180 \\
(\mathrm{n}, \%)\end{array}$ & $\begin{array}{l}15-30 \\
N=132 \\
(n, \%)\end{array}$ & $\begin{array}{l}>30 \\
\mathrm{~N}=280 \\
(\mathrm{n}, \%)\end{array}$ & \\
\hline Gender & & & & 0.046 \\
\hline Female & $42(23.3)$ & $40(30.3)$ & 54 (19.3) & \\
\hline Male & $138(76.7)$ & $92(69.7)$ & $226(80.7)$ & \\
\hline Age, years & & & & 0.831 \\
\hline$<65$ & $100(55.6)$ & $66(50.0)$ & $130(46.4)$ & \\
\hline$\geq 65$ & $80(44.4)$ & $66(50.0)$ & $150(53.6)$ & \\
\hline $\mathrm{BMI}, \mathrm{kg} / \mathrm{m}^{2}$ & & & & 0.001 \\
\hline$>30$ & $62(34.4)$ & $58(43.9)$ & $184(65.7)$ & \\
\hline $18-24.9$ & $30(16.7)$ & $12(9.1)$ & $12(4.3)$ & \\
\hline $25-30$ & $88(48.9)$ & $62(47.0)$ & $84(30.0)$ & \\
\hline ODI, events/hour & & & & 0.001 \\
\hline $0-16$ & $172(95.6)$ & $56(42.4)$ & $72(25.7)$ & \\
\hline $16.1-31$ & $4(2.2)$ & $74(56.1)$ & $200(71.4)$ & \\
\hline Smoking habit & & & & 0.04 \\
\hline Ex-smoker & $78(48.1)$ & $64(54.2)$ & $96(46.6)$ & \\
\hline Current smoker & $28(17.3)$ & $10(8.5)$ & $46(22.3)$ & \\
\hline Never smoker & $56(34.6)$ & $44(37.3)$ & $64(31.1)$ & \\
\hline \multicolumn{5}{|l|}{ Comorbidities } \\
\hline Hypertension & $76(42.2)$ & $82(62.1)$ & $154(55.0)$ & 0.001 \\
\hline Heart diseases & $48(26.7)$ & 28 (21.2) & $66(23.6)$ & 0.591 \\
\hline Respiratory & $44(24.4)$ & $32(24.2)$ & $48(17.1)$ & 0.221 \\
\hline Diabetes & $22(12.2)$ & $26(19.7)$ & $68(24.3)$ & 0.001 \\
\hline Anxiety/depression & $22(12.2)$ & $24(18.2)$ & $40(14.3)$ & 0.291 \\
\hline Endocrinology & $12(6.7)$ & $18(13.6)$ & $22(7.9)$ & 0.081 \\
\hline Cerebrovascular & $6(3.3)$ & $8(6.1)$ & $16(5.7)$ & 0.361 \\
\hline Lower limb arteriopathy & $8(4.4)$ & $8(6.1)$ & $8(2.9)$ & 0.351 \\
\hline
\end{tabular}

${ }^{\star}$ Eyes were considered the unit of analysis.

AHI, Apnoea/Hypopnoea Index; BMI, body mass index; ODI, Oxygen Desaturation Index; OSA, obstructive sleep apnoea.

reactive protein. ${ }^{20}$ An additional possible mechanism may involve minor trauma or mechanical stress ${ }^{42}$ due to the sleep preference for the involved side and/or nocturnal eyelid eversion. ${ }^{22}{ }^{23}$ Our study did not find any evidence of a higher prevalence of eyelid disorders in patients with different AHI levels. Only two previous studies report this correlation, although they have a small number of patients and only one evaluates patients following the American Academy of Sleep Medicine criteria. ${ }^{724}$

The second most frequent ED was corneal disorders. The six patients diagnosed with KC accounted for a prevalence of $2 \%$, in agreement with Mojon et al. ${ }^{7}$ This was a higher value compared with the $0.054 \%$ prevalence in the general population. ${ }^{25}$ Ectasia was also evaluated as a sign of early stage of subclinical KC. ${ }^{13}$ The results from our study showed for the first time that ectasia was associated with BMI, as expected, and also with the severity of OSA.
It is most likely that the aetiological mechanisms for this association are multifactorial. It has been suggested that MMPs and proteinase inhibitors may be causative factors for developing $\mathrm{KC}$ in healthy subject, as they lead to a reduction in corneal resistance and corneal hysteresis. ${ }^{26}$ In patients with OSA, the high serum levels and activity of MMPs or $\mathrm{C}$ reactive protein may well account for altered airway biomechanics, leading to repetitive collapse of the upper airway. ${ }^{20}$ The recurrence of hypoxic conditions may lead to anaerobic glycolysis and stromal acidosis, and may promote the transcription of proinflammatory cytokines, tumour necrosis factor- $\alpha$ or interleukin-6, leading to corneal thinning. ${ }^{28}{ }^{29}$ Indeed, the systemic low-grade chronic inflammation that affects obese patients may contribute to the development of corneal ectasia. Our study failed to confirm the hypoxic condition as cause of low-grade chronic inflammation 


\begin{tabular}{|c|c|c|}
\hline & n (\%) & $95 \% \mathrm{Cl}$ \\
\hline Eyelid disorders & $166(56.1)$ & 50.4 to 61.7 \\
\hline Eyelid laxity & $111(37.5)$ & 32.0 to 43.0 \\
\hline Floppy eyelid syndrome & $55(18.6)$ & 14.1 to 23.0 \\
\hline Corneal disorders & $80(27.0)$ & 22.0 to 32.1 \\
\hline Ectasia & $72(24.3)$ & 19.4 to 29.2 \\
\hline Keratoconus & $6(2.0)$ & 0.4 to 3.6 \\
\hline Pellucid marginal degeneration & $2(0.7)$ & 0.3 to 1.6 \\
\hline Macular disorders & $37(12.5)$ & 8.7 to 16.3 \\
\hline Epiretinal membrane & $21(7.1)$ & 4.2 to 10.0 \\
\hline $\begin{array}{l}\text { Age-related macular } \\
\text { degeneration }\end{array}$ & $16(5.4)$ & 2.8 to 8.0 \\
\hline Glaucoma & $33(11.1)$ & 7.6 to 14.7 \\
\hline Normal tension glaucoma & $28(9.5)$ & 6.1 to 12.8 \\
\hline Primary open-angle glaucoma & $5(1.7)$ & 0.2 to 3.2 \\
\hline $\begin{array}{l}\text { Non-arteritic anterior ischaemic } \\
\text { optic neuropathy }\end{array}$ & $3(1.0)$ & 0.1 to 2.2 \\
\hline Other & $11(3.7)$ & 1.6 to 5.9 \\
\hline Diabetic retinopathy & $4(1.4)$ & 0.0 to 2.7 \\
\hline Cerebral artery stroke & $2(0.7)$ & 0.3 to 1.6 \\
\hline Chorioretinitis & $1(0.3)$ & 0.3 to 1.0 \\
\hline Lenticopathy & $1(0.3)$ & 0.3 to 1.0 \\
\hline Retinal artery occlusion & $1(0.3)$ & 0.3 to 1.0 \\
\hline Retinitis pigmentosa & $1(0.3)$ & 0.3 to 1.0 \\
\hline Trauma & $1(0.3)$ & 0.3 to 1.0 \\
\hline
\end{tabular}

since we did not observe a higher prevalence in patients with higher AHI levels.

Macular disorders were also investigated and were the third most frequent ED in our patients with OSA. It resulted in threefold prevalence in our patients with OSA than what has been observed in the general population. Despite this higher prevalence, we did not find AHI levels as a risk factor for age related macular degeneration (AMD). The same prevalence of epiretinal membrane did not differ from that in the general population. ${ }^{30} 31$

The fourth most frequently observed ED was glaucoma. A large, multicentre, prospective cohort study in France does not show a significant influence of OSA diagnosis on the risk to develop glaucoma, while age $>61.4$ years, female gender, BMI $<30 \mathrm{~kg} / \mathrm{m}^{2}$, hypertension, high triglyceride levels or thyroid dysfunction are significantly associated with increased risk of glaucoma. ${ }^{32}$ In contrast a meta-analysis involving 2288701 participants shows that OSA is a risk factor for glaucoma, higher in Chinese population, female or younger population. ${ }^{33}$ Our study also found an increase prevalence in patients with severe AHI, exploring the relationship of the severity of OSA, as suggested in this meta-analysis. There was no difference in POAG prevalence in the general Italian and our study cohort. ${ }^{34}$ Whereas the prevalence for NTG was tenfold $(9.5 \%$ vs $0.6 \%$ in the
Table 3 Risk factors for eye diseases according to the levels of AHI

\begin{tabular}{|c|c|c|c|c|}
\hline $\begin{array}{l}\text { AHI, } \\
\text { events/ } \\
\text { hour }\end{array}$ & $\mathbf{N}$ & $\begin{array}{l}\text { Diseased } \\
\text { eyes, \% }\end{array}$ & $\begin{array}{l}\text { Multivariable } \\
\text { analysis* } \\
\text { OR }(95 \% \mathrm{Cl})\end{array}$ & Exact $p$ \\
\hline \multicolumn{5}{|c|}{ Eyelid disorders } \\
\hline $5-14.9$ & 180 & 44.0 & 1.00 & - \\
\hline $15-30$ & 132 & 52.0 & 1.27 (0.69 to 2.34$)$ & 0.42 \\
\hline$>30$ & 280 & 57.0 & 1.45 (0.85 to 2.47$)$ & 0.16 \\
\hline \multicolumn{5}{|c|}{ Corneal disorders } \\
\hline $5-14.9$ & 180 & 20.1 & 1.00 & - \\
\hline $15-30$ & 132 & 20.5 & 1.11 (0.51 to 2.40$)$ & 0.78 \\
\hline$>30$ & 280 & 26.0 & 1.74 (0.90 to 3.46$)$ & 0.09 \\
\hline \multicolumn{5}{|c|}{ Macular disorders } \\
\hline $5-14.9$ & 180 & 6.1 & 1.00 & - \\
\hline $15-30$ & 132 & 5.3 & 0.69 (0.25 to 1.90$)$ & 0.552 \\
\hline$>30$ & 280 & 10.4 & 1.27 (0.53 to 3.06$)$ & 0.587 \\
\hline \multicolumn{5}{|l|}{ Glaucoma } \\
\hline $5-14.9$ & 180 & 3.8 & 1.00 & - \\
\hline $15-30$ & 132 & 8.3 & 2.23 (0.78 to 6.39$)$ & 0.134 \\
\hline$>30$ & 280 & 10.0 & 2.50 (1.05 to 5.93$)$ & 0.037 \\
\hline
\end{tabular}

*Logistic model regression with clustering adjusted for sex, age and body mass index

$\mathrm{AHI}$, apnoea/hypopnoea index.

general population), there was also a fivefold increased prevalence of glaucoma in our patients with OSA and an increased risk of glaucoma, which was statistically significantly related to the OSA severity and advancing age. The aetiological mechanisms for the association between OSA and glaucoma remain to be clarified. Vascular theory postulates patients with OSA have a collapse of the upper airway during sleep, leading to repeated and prolonged episodes of hypoxia-reperfusion. This may reduce the oxygen supply to the optic nerve with subsequent optic neuropathy. ${ }^{35}$ Hypoxia may also increase intracranial pressure, which in turn may decrease cerebral and optic nerve perfusion. ${ }^{36}$ The mechanical theory proposes that OSA has the potential to raise the IOP through changes in sleep architecture and an increase in sympathetic tone. This increased IOP may lead to axon damage of the optic nerve. Other theories, such as inflammation and oxidative stress, have also been put forward. ${ }^{37}$ All these theories describe the occurrence of optic nerve damage, which does not depend on an increase in the IOP and might explain the tenfold increased prevalence of NTG observed in our patients with OSA compared with the general population. This is also supported by a relative risk of 3.34 to have OSA in patients with NTG compared with systemic risk factors-matched subjects. ${ }^{38}$

NAION was the least frequently observed ED. Although the underlying pathophysiological mechanisms of NAION have not yet been fully elucidated, it has been hypothesised that there is a circulatory insufficiency within the optic nerve head during a nocturnal non-dipping blood pressure 
profile promoted by OSA. Indeed, OSA is a risk factor for NAION, and it has been reported that patients run a sixfold risk of developing NAION than subjects without OSA. ${ }^{39}$ Several studies have investigated the increased prevalence of OSA in patients with NAION, some showing OSA as a risk factor, other as a contributing factor to established vascular endothelium defects that can damage autoregulation of optic nerve head blood flow. ${ }^{64041}$ To the best of our knowledge, there is only one study that has previously evaluated the prevalence of NAION in an OSA population. Moreover, this study uses a large administrative databases and not medical records, leading to several limitations. ${ }^{42}$ Our study confirmed a twofold prevalence of NAION in OSA population compared with the general population. ${ }^{43}$

To have performed portable monitoring PSG was the major limitation of our study. Portable PSG underestimates AHI compared with in-laboratory PSG. However, portable PSG is not inferior to in-laboratory PSG for a diagnosis of OSA and can be used in the majority of patients with suspected sleep apnoea with lower costs. ${ }^{44}$

In conclusion, our data showed that only glaucoma was significantly associated with severe AHI. Therefore, we are of the opinion that any previous diagnosis or suspicion of OSA should be thoroughly assessed by an ophthalmologist during ophthalmic examination, due to the implications in the management of increased eyelid laxity and FES, corneal refraction, macular degeneration or, above all, glaucoma. Hopefully this report will prompt further research on the underlying mechanisms involved in the association between EDs and OSA.

Acknowledgements The authors thank Barbara Wade for her linguistic advice. Contributors Study design: EP, ADG, CLD, GM, MF. Research conduction: CLD, EP. Data collection: CLD, EB, FB, PPDS, MP. Data analysis: AF, NG. Manuscript writing: EP, CLD, AF. Manuscript approval: MF, GM.

Disclaimer The Corresponding Author affirms that the manuscript is an honest, accurate and transparent account of the study reported; that no important aspects of the study have been omitted; and that any discrepancies from the study as planned (and, if relevant, registered) have been explained.

Competing interests None declared

Patient consent Obtained.

Ethics approval Institutional review board.

Provenance and peer review Not commissioned; externally peer reviewed.

Data sharing statement No additional data are available.

Open Access This is an Open Access article distributed in accordance with the Creative Commons Attribution Non Commercial (CC BY-NC 4.0) license, which permits others to distribute, remix, adapt, build upon this work non-commercially, and license their derivative works on different terms, provided the original work is properly cited and the use is non-commercial. See: http://creativecommons.org/ licenses/by-nc/4.0/

(C) Article author(s) (or their employer(s) unless otherwise stated in the text of the article) 2017. All rights reserved. No commercial use is permitted unless otherwise expressly granted.

\section{REFERENCES}

1. Sleep-related breathing disorders in adults: recommendations for syndrome definition and measurement techniques in clinical research. The Report of an American Academy of Sleep Medicine Task Force. Sleep 1999;22:667-89.
2. Cho JH, Choi JH, Suh JD, et al. Comparison of anthropometric data between asian and caucasian patients with obstructive sleep apnea: a meta-analysis. Clin Exp Otorhinolaryngol 2016;9:1-7.

3. Garvey JF, Pengo MF, Drakatos P, et al. Epidemiological aspects of obstructive sleep apnea. J Thorac Dis 2015;7:920-9.

4. McNab AA. Floppy eyelid syndrome and obstructive sleep apnea. Ophthal Plast Reconstr Surg 1997;13:98-114.

5. Robert PY, Adenis JP, Tapie P, et al. Eyelid hyperlaxity and obstructive sleep apnea (O.S.A.) syndrome. Eur J Ophthalmol 1997;7:211-5.

6. Huon LK, Liu SY, Camacho M, et al. The association between ophthalmologic diseases and obstructive sleep apnea: a systematic review and meta-analysis. Sleep Breath 2016;20:1145-54.

7. Mojon DS, Goldblum D, Fleischhauer J, et al. Eyelid, conjunctival, and corneal findings in sleep apnea syndrome. Ophthalmology 1999;106:1182-5.

8. Wang P, Yu DJ, Feng G, et al. Is Floppy Eyelid Syndrome More Prevalent in Obstructive Sleep Apnea Syndrome Patients? J Ophthalmol 2016;2016:6980281-9.

9. Shi Y, Liu P, Guan J, et al. Association between glaucoma and obstructive sleep apnea syndrome: a meta-analysis and systematic review. PLoS One 2015;10:e0115625.

10. Fraser CL. Obstructive sleep apnea and optic neuropathy: is there a link? Curr Neurol Neurosci Rep 2014;14:465.

11. Collop NA, Anderson WM, Boehlecke B, et al. Clinical guidelines for the use of unattended portable monitors in the diagnosis of obstructive sleep apnea in adult patients. Portable Monitoring Task Force of the American Academy of Sleep Medicine. J Clin Sleep Med 2007;3:737-47.

12. Grigg-Damberger MM. The AASM Scoring Manual four years later. $J$ Clin Sleep Med 2012;8:323-32.

13. Gomes JA, Tan D, Rapuano CJ, et al. Global consensus on keratoconus and ectatic diseases. Cornea 2015;34:359-69.

14. Kersey $\mathrm{T}$, Clement $\mathrm{Cl}$, Bloom $\mathrm{P}$, et al. New trends in glaucoma risk, diagnosis \& management. Indian J Med Res 2013;137:659-68.

15. Grover S, Murthy RK, Brar VS, et al. Normative data for macular thickness by high-definition spectral-domain optical coherence tomography (spectralis). Am J Ophthalmol 2009;148:266-71.

16. Murthy RK, Diaz M, Chalam KV, et al. Normative data for macular volume with high-definition spectral-domain optical coherence tomography (Spectralis). Eur J Ophthalmol 2015;25:546-51.

17. Kadyan A, Asghar J, Dowson L, et al. Ocular findings in sleep apnoea patients using continuous positive airway pressure. Eye 2010;24:843-50.

18. Culbertson WW, Ostler HB. The floppy eyelid syndrome. Am J Ophthalmol 1981;92:568-75.

19. Wong WL, Su X, Li X, et al. Global prevalence of age-related macular degeneration and disease burden projection for 2020 and 2040: a systematic review and meta-analysis. Lancet Glob Health 2014;2: e106-16.

20. Ye J, Liu H, Li Y, et al. Increased serum levels of $\mathrm{C}$-reactive protein and matrix metalloproteinase-9 in obstructive sleep apnea syndrome. Chin Med J 2007:120:1482-6.

21. Swartz MA, Tschumperlin DJ, Kamm RD, et al. Mechanical stress is communicated between different cell types to elicit matrix remodeling. Proc Natl Acad Sci U S A 2001;98:6180-5.

22. Fowler AM, Dutton JJ. Floppy eyelid syndrome as a subset of lax eyelid conditions: relationships and clinical relevance (an ASOPRS thesis). Ophthal Plast Reconstr Surg 2010;26:195-204.

23. Lema I, Sobrino T, Durán JA, et al. Subclinical keratoconus and inflammatory molecules from tears. Br J Ophthalmol 2009;93:820-4.

24. Acar M, Firat $\mathrm{H}$, Acar $\mathrm{U}$, et al. Ocular surface assessment in patients with obstructive sleep apnea-hypopnea syndrome. Sleep Breath 2013;17:583-8.

25. Kennedy RH, Bourne WM, Dyer JA. A 48-year clinical and epidemiologic study of keratoconus. Am J Ophthalmol 1986;101:267-73.

26. Balasubramanian SA, Pye DC, Willcox MD. Are proteinases the reason for keratoconus? Curr Eye Res 2010;35:185-91.

27. Molina FD, Santos FC, Falleiros LR, et al. Microscopical evaluation of extracellular matrix and its relation to the palatopharyngeal muscle in obstructive sleep apnea. Microsc Res Tech 2011;74:430-9.

28. Ang $\mathrm{JH}$, Efron N. Corneal hypoxia and hypercapnia during contact lens wear. Optom Vis Sci 1990;67:512-21.

29. Taylor CT. Interdependent roles for hypoxia inducible factor and nuclear factor-kappaB in hypoxic inflammation. $J$ Physiol 2008;586:4055-9.

30. Reibaldi M, Longo A, Pulvirenti A, et al. Geo-Epidemiology of AgeRelated Macular Degeneration: New Clues Into the Pathogenesis. Am J Ophthalmol 2016;161:78-93. 
31. Bu SC, Kuijer R, Li XR, et al. Idiopathic epiretinal membrane. Retina 2014;34:2317-35.

32. Aptel F, Chiquet C, Tamisier R, et al. Association between glaucoma and sleep apnea in a large French multicenter prospective cohort. Sleep Med 2014;15:576-81.

33. Liu S, Lin Y, Liu X. Meta-Analysis of Association of Obstructive Sleep Apnea With Glaucoma. J Glaucoma 2016;25:1-7.

34. Bonomi L, Marchini G, Marraffa M, et al. Prevalence of glaucoma and intraocular pressure distribution in a defined population. The EgnaNeumarkt Study. Ophthalmology 1998;105:209-15.

35. Lin CC, Hu CC, Ho JD, et al. Obstructive sleep apnea and increased risk of glaucoma: a population-based matched-cohort study. Ophthalmology 2013;120:1559-64.

36. Nusbaum DM, Wu SM, Frankfort BJ. Elevated intracranial pressure causes optic nerve and retinal ganglion cell degeneration in mice. Exp Eye Res 2015;136:38-44

37. Faridi O, Park SC, Liebmann JM, et al. Glaucoma and obstructive sleep apnoea syndrome. Clin Exp Ophthalmol 2012;40:408-19.

38. Bilgin G. Normal-tension glaucoma and obstructive sleep apnea syndrome: a prospective study. BMC Ophthalmol 2014;14:27.
39. Wu Y, Zhou LM, Lou H, et al. The Association Between Obstructive Sleep Apnea and Nonarteritic Anterior Ischemic Optic Neuropathy: A Systematic Review and Meta-Analysis. Curr Eye Res 2016;41:987-92.

40. Arda H, Birer S, Aksu M, et al. Obstructive sleep apnoea prevalence in non-arteritic anterior ischaemic optic neuropathy. Br J Ophthalmol 2013;97:206-9.

41. Bilgin G, Koban Y, Arnold AC. Nonarteritic anterior ischemic optic neuropathy and obstructive sleep apnea. J Neuroophthalmol 2013;33:232-4

42. Stein JD, Kim DS, Mundy KM, et al. The association between glaucomatous and other causes of optic neuropathy and sleep apnea. Am J Ophthalmol 2011;152:989-98.

43. Lee MS, Grossman D, Arnold AC, et al. Incidence of nonarteritic anterior ischemic optic neuropathy: increased risk among diabetic patients. Ophthalmology 2011;118:959-63.

44. Corral J, Sanchez-Quiroga MA, Carmona-Bernal C, et al. Spanish Sleep Network. Conventional Polysomnography is Not Necessary for the Management of Most Patients with Suspected Obstructive Sleep Apnea. Am J Respir Crit Care Med 2017. 